\section{Commentary: Truncal valve insufficiency: The dilemma between limiting challenges and challenging limits}

\author{
Bahaaldin Alsoufi, MD
}

Truncal valve anomalies are common in neonates born with persistent truncus arteriosus (PTA). As a result, truncal valve insufficiency (TVI) is often present at various degrees, with nearly $15 \%$ having moderate to severe insufficiency. ${ }^{1,2}$ In many published reports, significant TVI is associated with diminished survival. ${ }^{3,4}$ On the other hand, truncal valvuloplasty (TVP) is challenging, especially when performed in neonates and small infants in whom it is also associated with death risk. ${ }^{1,5,6}$ Naimo and colleagues $^{7}$ from Melbourne provide a review of recent literature on TVP. They describe various TVP strategies and focus on outcomes such as early repair success and longevity, operative death, and late attrition.

In their review, the authors demonstrate that TVP continues to be associated with high early death (19\% in their personal experience, up to $44 \%$ in other series), late attrition $(10 \%-20 \%)$, and high truncal valve reoperation need (at least 50\% at long-term follow-up). ${ }^{7}$ Although these results are disappointing, one can argue that they might not reflect current expectations, given that the majority of these single-institution studies spanned very long periods. Nonetheless, in a recent study of the Society of Thoracic Surgeons database that included patients from 2000 to 2009, Russell and colleagues ${ }^{1}$ demonstrated that operative death in neonates who received simultaneous PTA repair

\footnotetext{
From the Division of Pediatric Cardiothoracic Surgery, Department of Cardiovascular and Thoracic Surgery, University of Louisville School of Medicine, Norton Children's Hospital, Louisville, Ky.

Disclosures: The author reported no conflicts of interest.

The Journal policy requires editors and reviewers to disclose conflicts of interest and to decline handling or reviewing manuscripts for which they may have a conflict of interest. The editors and reviewers of this article have no conflicts of interest.

Received for publication Nov 14, 2020; revisions received Nov 14, 2020; accepted for publication Nov 16, 2020; available ahead of print Nov 25, 2020.

Address for reprints: Bahaaldin Alsoufi, MD, Division of Pediatric Cardiothoracic Surgery, Department of Cardiovascular and Thoracic Surgery, University of Louisville School of Medicine, Norton Children's Hospital, 201 Abraham Flexner Way, Suite 1200, Louisville, KY 40202 (E-mail: balsoufi@hotmail.com).

J Thorac Cardiovasc Surg 2021;162:1343-4

$0022-5223 / \$ 36.00$

Copyright (c) 2020 by The American Association for Thoracic Surgery

https://doi.org/10.1016/j.jtcvs.2020.11.065
}

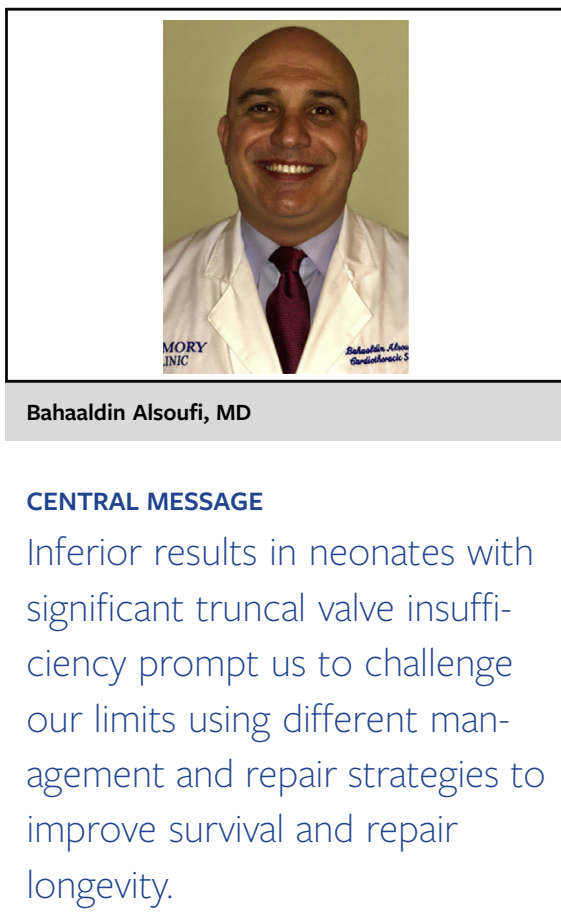

and TVP was $30 \%$ (vs $10 \%$ in those who did not receive concomitant TVP) and that delayed truncal valve surgery during the same admission was associated with $100 \%$ operative death. These results suggest that despite the recent advances in the perioperative management of complex neonates, we continue to struggle with this subset of challenging patients. Again, the 2 major confounding issues with TVP seem to be high operative death when TVP is performed in neonates alongside or shortly after surgical repair of PTA, and high truncal valve reoperation need.

The first issue of high operative death is complex and starts with the decision-making process with regard to the indication for TVP. In neonates with mild or mild+ TVI, it is generally safe not to intervene on the truncal valve at time of PTA repair. In those with more significant TVI, the decision is more difficult. One could limit the challenges and stay out of trouble by avoiding concomitant TVP, given the technical difficulties and associated high operative death. On the other hand, significant TVI is high risk for operative death irrespective of TVP, and the need to reoperate on the truncal valve soon after neonatal PTA repair is also associated with increased technical difficulties and high operative death (up to $100 \%$ if performed during the same admission in the Society of Thoracic Surgeons database review by Russell and colleagues ${ }^{2}$ ). That is an argument in favor of confronting our challenges and having a low threshold to concomitantly intervene on the truncal 
valve at time of PTA repair. The question is, Why is TVP in neonates associated with such a high mortality? Although TVP requires longer cardiopulmonary bypass and ischemic durations, I suspect that this is not necessarily a contributing factor in the current era. Other complex and prolonged surgeries such as Taussig-Bing repair or double switch operations require very long cardiopulmonary bypass and ischemic durations but are currently associated with lower operative death risk owing to advances in perfusion and myocardial protection techniques. ${ }^{8}$ I suspect that the issue is a combination of poor preoperative condition and residual lesions, namely TVI. Persistent significant TVI results in continuous volume load in the setting of biventricular diastolic dysfunction, and subsequent diastolic runoff and consequent effects on coronary and other organ perfusion. The existing literature does not provide granular information about the association between residual TVI and early risk in these patients, but in my experience managing such patients, the ones who had successful TVP did well, whereas those who did not did poorly, irrespective of the operation length. Accordingly, an assumption that elimination of this residual lesion might improve survival makes sense; but how can we reach that? Based on the review by Naimo and colleagues, ${ }^{7}$ it seems that several groups have acquired advanced skills in neonatal aortic valve repair in general and TVP more specifically, prompting others to adopt similar strategies and hopefully duplicate or even improve on these results. Moreover, based on this philosophy, I believe that lower threshold to perform timely truncal valve replacement, even concomitantly with PTA repair if TVP is unsuccessful, might be a better option than leaving a neonate with significant residual TVI. In my experience with a handful of cases, lower threshold to perform truncal valve replacement (as opposed to accepting significant TVI with the hope that it would be tolerated for a while) paid off, allowing the neonates to survive to hospital discharge. Although challenging, experienced neonatal surgeons are capable of dealing with coronary variations commonly seen in patients with PTA and getting these neonates through a complex and relatively more prolonged operation. This would obviously be a temporizing solution that commits these neonates to lifelong need for complex reoperations, but in my opinion and experience this seems to be a better option in a very challenging situation.

The second reality of TVP that might also warrant that we challenge our limits is the high truncal valve reoperation need. More and more, surgeons demonstrate improved results with aortic valve repair techniques that follow different philosophies; some of them are based on leaflet preservation, whereas others are based on leaflet excision or augmentation. ${ }^{9}$ Several of these repair techniques can be applied on the truncal valves, especially in older patients, and we might likely learn of better TVP durability with these techniques as we obtain longer follow-up.

\section{References}

1. Jacobs ML. Congenital heart surgery nomenclature and database project: truncus arteriosus. Ann Thorac Surg. 2000;69(4 Suppl):S50-5.

2. Russell HM, Pasquali SK, Jacobs JP, Jacobs ML, O'Brien SM, Mavroudis C, et al. Outcomes of repair of common arterial trunk with truncal valve surgery: a review of the Society of Thoracic Surgeons congenital heart surgery database. Ann Thorac Surg. 2012;93:164-9.

3. Rajasinghe HA, McElhinney DB, Reddy VM, Mora BN, Hanley FL. Long-term follow-up of truncus arteriosus repaired in infancy: a twenty-year experience. J Thorac Cardiovasc Surg. 1997;113:869-79.

4. Di Donato R, Fyfe D, Puga F, Danielson G, Ritter D, Edwards W, et al. Fifteenyear experience with surgical repair of truncus arteriosus. J Thorac Cardiovasc Surg. 1985;89:414-22.

5. Bakar AM, Costello JM, Sassalos P, Amula V, Buckley JR, Smerling AJ, et al. Multicenter analysis of truncal valve management and outcomes in children with truncus arteriosus. Pediatr Cardiol. 2020;41:1473-83.

6. Naimo PS, Fricke TA, d'Udekem Y, Brink J, Weintraub RG, Brizard CP, et al. Impact of truncal valve insufficiency on the outcomes of truncus arteriosus repair. Eur J Cardiothorac Surg. 2018;54:524-31.

7. Naimo PS, Buratto E, Konstantinov IE. Truncal valve repair in children. J Thorac Cardiovasc Surg. 2021;162:1337-42.

8. Alsoufi B, Cai S, Williams WG, Coles JG, Caldarone CA, Redington AM, et al Improved results with single-stage total correction of Taussig-Bing anomaly Eur J Cardiothorac Surg. 2008;33:244-50.

9. Alsoufi B. Commentary: truncal valve repair-different philosophies drive different strategies. J Thorac Cardiovasc Surg. November 5, 2019 [Epub ahead of print]. 